\title{
Efficacy of a short cognitive training program in patients with multiple sclerosis
}

\author{
This article was published in the following Dove Press journal: \\ Neuropsychiatric Disease and Treatment \\ 3 February 2017 \\ Number of times this article has been viewed
}

\section{María Yaiza Pérez-Martín' \\ Montserrat González- \\ Platas' \\ Pablo Eguía-del Río \\ Cristina Croissier-Elías' \\ Alejandro Jiménez Sosa ${ }^{3}$}

'Service of Neurology, Complejo Hospitalario Universitario de

Canarias, La Laguna, ${ }^{2}$ Service of Neurology, Doctor José Molina Orosa Hospital, Arrecife, Lanzarote, ${ }^{3}$ Unit of Research, Complejo Hospitalario Universitario de Canarias, La Laguna, Spain

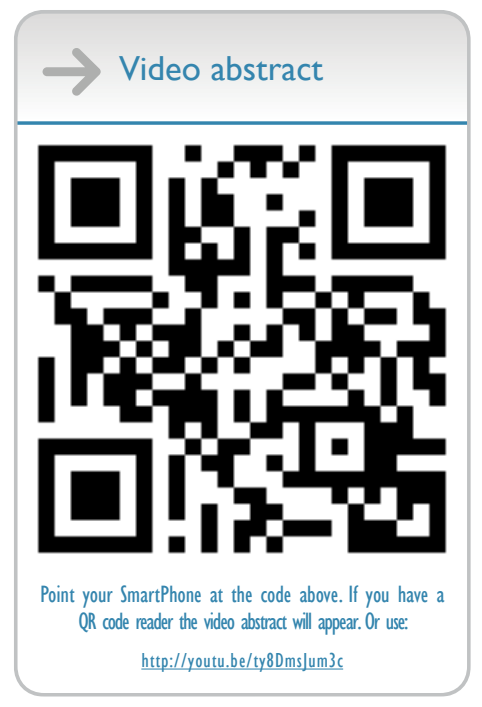

Correspondence: María Yaiza Pérez-Martín Service of Neurology, Hospital Universitario de Canarias, Ofra, s/n, La Laguna 38320, Santa Cruz de Tenerife, Spain

Tel +34616464403

Fax +34922 31 927I

Email yaizaneuro@hotmail.com
Background: Cognitive impairment is a common feature in multiple sclerosis (MS) and may have a substantial impact on quality of life. Evidence about the effectiveness of neuropsychological rehabilitation is still limited, but current data suggest that computer-assisted cognitive training improves cognitive performance.

Objective: The objective of this study was to evaluate the efficacy of combined computerassisted training supported by home-based neuropsychological training to improve attention, processing speed, memory and executive functions during 3 consecutive months.

Methods: In this randomized controlled study blinded for the evaluators, 62 MS patients with clinically stable disease and mild-to-moderate levels of cognitive impairment were randomized to receive a computer-assisted neuropsychological training program $(n=30)$ or no intervention (control group [CG]; $\mathrm{n}=32$ ). The cognitive assessment included the Brief Repeatable Battery of Neuropsychological Test. Other secondary measures included subjective cognitive impairment, anxiety and depression, fatigue and quality of life measures.

Results: The treatment group (TG) showed significant improvements in measures of verbal memory, working memory and phonetic fluency after intervention, and repeated measures analysis of covariance revealed a positive effect in most of the functions. The control group (CG) did not show changes. The TG showed a significant reduction in anxiety symptoms and significant improvement in quality of life. There were no improvements in fatigue levels and depressive symptoms. Conclusion: Cognitive intervention with a computer-assisted training supported by home training between face-to-face sessions is a useful tool to treat patients with MS and improve functions such as verbal memory, working memory and phonetic fluency.

Keywords: multiple sclerosis, cognitive training, cognitive impairment, rehabilitation

\section{Introduction}

Multiple sclerosis (MS) is an inflammatory degenerative disease of the central nervous system (CNS), which is thought to be largely caused by autoimmune processes that produce loss of myelin in the white matter of the cerebral hemispheres, brainstem, cerebellum, spinal cord and optic nerves. Because of the widespread nature of the MS lesions within the CNS, the illness presents a broad range of symptoms, which include loss of vision, tremor, ataxia, sphincter dysfunction, neuropsychiatric symptoms and cognitive impairment, among others.

Recent studies show that cognitive decline in MS can be attributed not only to the involvement of the white matter but also to the pathology of the gray matter. ${ }^{1-3}$

Cognitive impairment is a frequent feature of MS affecting up to $65 \%$ of patients, ${ }^{4}$ at both the earlier and later stages of the disease, ${ }^{5}$ and it tends to worsen over time. ${ }^{6}$

MS negatively affects several aspects of cognitive functions, including attention, information processing, ${ }^{7}$ learning and memory, executive function and visuospatial 
Table I Cognitive intervention studies

\begin{tabular}{|c|c|c|c|c|c|}
\hline Studies & Participants & $\begin{array}{l}\text { Cognitive } \\
\text { domains }\end{array}$ & $\begin{array}{l}\text { Duration, } \\
\text { frequency }\end{array}$ & Techniques & Results \\
\hline Brissart et $\mathrm{al}^{21}$ & $\begin{array}{l}\text { TG: } 10 \\
\text { CG: } 10\end{array}$ & Multiple skills & $\begin{array}{l}6 \text { months, } \\
2 / \text { month }\end{array}$ & Computer-assisted program & $\begin{array}{l}\text { TG showed improvements in verbal } \\
\text { memory, visual memory, working } \\
\text { memory, verbal fluency and language }\end{array}$ \\
\hline Mattioli et al ${ }^{49}$ & $\begin{array}{l}\text { TG: } 10 \\
\text { CG: } 10\end{array}$ & $\begin{array}{l}\text { Attention } \\
\text { executive } \\
\text { functions }\end{array}$ & $\begin{array}{l}12 \text { weeks, } \\
3 / \text { week }\end{array}$ & Computer-assisted program & $\begin{array}{l}\text { TG showed improvements in attention, } \\
\text { information processing, executive } \\
\text { functions and depressive scores }\end{array}$ \\
\hline Shatil et $\mathrm{al}^{20}$ & $\begin{array}{l}\text { TG: } 24 \\
\text { CG: } 22\end{array}$ & Multiple skills & $\begin{array}{l}12 \text { weeks, } \\
3 / \text { week }\end{array}$ & Computer-assisted program & $\begin{array}{l}\text { TG improved memory-based cognitive } \\
\text { abilities, speed of information recall, } \\
\text { focused attention and visuomotor vigilance }\end{array}$ \\
\hline $\begin{array}{l}\text { Plohmann } \\
\text { et al }{ }^{15}\end{array}$ & TG: 22 & Attention & $2 \times 3$ weeks & Computer-assisted retraining & $\begin{array}{l}\text { The group showed significant } \\
\text { improvement in cognitive performance } \\
\text { and daily functioning }\end{array}$ \\
\hline $\begin{array}{l}\text { De Giglio } \\
\text { et } \mathrm{al}^{23}\end{array}$ & $\begin{array}{l}\text { TG: } 18 \\
\text { CG: } 17\end{array}$ & Multiple skills & 8 weeks & $\begin{array}{l}\text { Home-based cognitive } \\
\text { rehabilitation program based on } \\
\text { the video game Dr Kawashima's } \\
\text { Brain Training }\end{array}$ & $\begin{array}{l}\text { TG improved cognitive functions, some } \\
\text { aspects of QoL and cognitive fatigue }\end{array}$ \\
\hline Amato et $\mathrm{al}^{16}$ & $\begin{array}{l}\text { TG: } 55 \\
\text { CG: } 33\end{array}$ & Attention & $\begin{array}{l}12 \text { weeks, } \\
2 / \text { week }\end{array}$ & $\begin{array}{l}\text { Computer-assisted program: } \\
\text { specific vs nonspecific training }\end{array}$ & $\begin{array}{l}\text { Improvements in the PASAT (working } \\
\text { memory) with specific training }\end{array}$ \\
\hline $\begin{array}{l}\text { Chiaravalloti } \\
\text { et } \text { al }^{18}\end{array}$ & $\begin{array}{l}\text { TG: } 4 \text { I } \\
\text { CG: } 4 \text { I }\end{array}$ & $\begin{array}{l}\text { Memory and } \\
\text { learning }\end{array}$ & 10 sessions & $\mathrm{mSMT}$ & $\begin{array}{l}\text { Significant improved learning, everyday } \\
\text { memory, general contentment and family } \\
\text { report of apathy and executive functions }\end{array}$ \\
\hline $\begin{array}{l}\text { Rosti-Otajärvi } \\
\text { et } \mathrm{al}^{22}\end{array}$ & $\begin{array}{l}\text { TG: } 50 \\
\text { CG: } 28\end{array}$ & Multiple skills & $\begin{array}{l}\text { I3 weeks, } \\
\text { I/week }\end{array}$ & $\begin{array}{l}\text { Computer-assisted } \\
\text { program: strategy-oriented } \\
\text { neuropsychological rehabilitation }\end{array}$ & $\begin{array}{l}\text { Positive effects on perceived cognitive } \\
\text { deficits maintained after } 9 \text { months }\end{array}$ \\
\hline $\begin{array}{l}\text { Stuifbergen } \\
\text { et al }{ }^{19}\end{array}$ & $\begin{array}{l}\text { TG: } 34 \\
\text { CG: } 27\end{array}$ & $\begin{array}{l}\text { Memory, } \\
\text { attention and } \\
\text { problem solving }\end{array}$ & $\begin{array}{l}8 \text { weeks, } \\
3 / \text { week }\end{array}$ & $\begin{array}{l}\text { Computer-assisted program } \\
\text { combined with eight group } \\
\text { meetings }\end{array}$ & $\begin{array}{l}\text { Effects on verbal memory and } \\
\text { compensatory strategies }\end{array}$ \\
\hline $\begin{array}{l}\text { Mäntynen } \\
\text { et } \mathrm{al}^{24}\end{array}$ & $\begin{array}{l}\text { TG: } 58 \\
\text { CG: } 40\end{array}$ & Multiple skills & $\begin{array}{l}\text { I } 3 \text { weeks, } \\
\text { I/week }\end{array}$ & $\begin{array}{l}\text { Computer-assisted } \\
\text { program: strategy-oriented } \\
\text { neuropsychological rehabilitation }\end{array}$ & $\begin{array}{l}\text { TG did not improve cognitive } \\
\text { performance but had a positive effect on } \\
\text { perceived cognitive deficits }\end{array}$ \\
\hline Cerasa et al $^{17}$ & $\begin{array}{l}\text { TG: } 12 \\
\text { CG: II }\end{array}$ & Attention & $\begin{array}{l}6 \text { weeks, } \\
2 / \text { week }\end{array}$ & Computer-assisted program & Improvement in attention abilities \\
\hline
\end{tabular}

Abbreviations: TG, treatment group; CG, control group; mSMT, modified Story Memory Technique; PASAT, Paced Auditory Serial Addition Test; QoL, quality of life.

abilities, ${ }^{8}$ causing an important impact on quality of life, ${ }^{9-11}$ employment status, ${ }^{12}$ daily functioning, independence ${ }^{13}$ and participation in social activities. ${ }^{14}$ For this reason, the alleviation of deficits in cognitive functioning should be the main goal in MS research.

Systematic reviews on cognitive rehabilitation in MS have not found evidence to support its effectiveness. Hence, a recent review of the Cochrane Database found low-level evidence for positive effects of neuropsychological rehabilitation in MS, probably due to the fact that interventions and outcome measures included were heterogeneous, which limited the comparability of the studies. ${ }^{13}$ However, some studies show that neuropsychological rehabilitation may have favorable effects on patients' cognitive performance. Specifically, there is some evidence that individual computerassisted cognitive rehabilitation improves performance in neuropsychological tests.
Some of the studies have focused on specific attention training ${ }^{15-17}$ or memory, ${ }^{18,19}$ while others have shown a positive effect on multiple skills. ${ }^{20-24}$ Table 1 lists some of the major studies on the topic.

We have developed a multi-domain computer-assisted cognitive rehabilitation program supported by independent home-based work intended to generalize the strategies. The main objective was to assess the effectiveness of the rehabilitation program in patients with mild/moderate cognitive impairment. Additionally, we studied the effects of the program on emotional variables, perception of fatigue and cognitive impairment, and we analyzed the impact on quality of life.

\section{Methods}

The study was conducted in accordance with the principles of the Declaration of Helsinki ${ }^{25}$ and good clinical practice 
standards and was approved by the ethics committee for clinical research of the University Hospital of the Canary Islands. All participants provided written informed consent to participate.

\section{Patients and design}

A randomized, controlled, 3-month study blinded for the evaluators was conducted in the Service of Neurology of the Complejo Hospitalario Universitario de Canarias (Tenerife) and in the Service of Neurology of the Doctor José Molina Orosa Hospital (Lanzarote). The study was conducted between October 2013 and June 2015.

An incidental sample obtained from the population of patients with MS treated at the Service of Neurology of two tertiary hospitals was recruited.

Inclusion was based on the following criteria:

1. MS diagnosis according to the revised McDonald criteria; ${ }^{26}$

2. being older than 18 years;

3. having an Expanded Disability Status Scale (EDSS) ${ }^{27}$ score $\leq 7.0$ to prevent the inclusion of patients who may have difficulty traveling to the center in the rehabilitation phase;

4. subjective complaints about cognitive problems; this information was taken into account to promote adherence to the training program and

5. objective cognitive impairment defined as a performance of 1.5 standard deviation lower than the mean in a control group (CG) in at least two cognitive tests (determined by the neuropsychological assessment).

Participants were excluded if:

1. they had a diagnosis of current or past severe psychiatric disorder;

2. they had a relapse or had taken steroids within the 3 months prior to inclusion based on their clinical history;

3. they had previously participated in any cognitive rehabilitation program and

4. they met the criteria for the diagnosis of dementia. ${ }^{28}$

\section{Measurements and variables}

The Brief Repeatable Battery of Neuropsychological Test $(\mathrm{BRB}-\mathrm{N})^{29}$ was used to assess abilities in various cognitive domains. The battery consists of five tests: Selective Reminding Test (SRT) ${ }^{30}$ as a measure of verbal learning and delayed recall, which included long-term storage (SRT-LTS), consistent long-term retrieval (SRT-CLTR) and delayed recall (SRT-DR); the 10/36 Spatial Recall Test, ${ }^{31}$ an extended version of the original form and the 7/24
Spatial Recall Test that assesses visuospatial learning and delayed recall (SPART-T and SPART-DR); the Symbol Digit Modalities Test (SDMT) ${ }^{32}$ as a measure of complex attention and processing speed; the Paced Auditory Serial Addition Test (PASAT) ${ }^{33}$ that assesses sustained attention and working memory and the Controlled Oral Word Association Test (COWAT) ${ }^{34}$ that assesses verbal fluency. Normative values were adopted in accordance with Sepulcre et $\mathrm{a}^{35}$ and Troyer. ${ }^{36}$

Other instruments were used to measure the possible influence of the training on different aspects of MS: the Multiple Sclerosis Neuropsychological Questionnaire (MSNQ), ${ }^{37}$ the Fatigue Severity Scale (FSS), ${ }^{38}$ the Hospital Anxiety and Depression Scale (HADS) ${ }^{39}$ and the Multiple Sclerosis Quality of Life-54 (MSQoL-54). ${ }^{40}$

The neuropsychological battery and the questionnaires were administrated by a neuropsychologist familiar with the administration of all the tests. Alternative forms of the neuropsychological battery were used at baseline and after intervention program, in order to control test-retest effects and learning effects. The neuropsychologist who performed the posttreatment cognitive assessment was blinded to the group allocation of the patients.

\section{Intervention procedure}

The 62 participants included in the study were randomly assigned to either the intervention group or the CG.

The wait-list CG received no treatment. This group received information about their cognitive status and received a booklet containing a set of guidelines and general advice on the influence of habits and lifestyles on cognitive functions. The CG was contacted once a week.

The treatment group (TG) received cognitive training for a total of 12 weekly consecutive sessions, each lasting 60-75 minutes.

The rehabilitation program was focused on attention, processing speed, memory and executive functions through computerized and paper and pencil tasks designed by the members of the research team (all tasks were different to evaluation procedures to prevent the effect of practice). In order to ensure homogeneity, all sessions were standardized for all patients.

The sessions included 10 minutes to evaluate the generalization of prior training to activities of daily life and control and/or correction of assignment notebooks delivered in the previous session and 50 minutes of working with the patients. The last 10-15 minutes consisted of feedback on the performance and relevance of the work and a review of work 
Table 2 Functions trained in each session

\begin{tabular}{ll}
\hline Session & Cognitive functions \\
\hline 1 & Attention, processing speed and inhibition \\
2 & Attention, processing speed, inhibition and visual memory \\
3 & Attention and verbal memory \\
4 & Memory of names and organization \\
5 & Attention, processing speed and learning \\
6 & Visuospatial memory and calculation \\
7 & Working memory and concentration \\
8 & Working memory and organization \\
9 & Sustained attention and visual memory \\
10 & Processing speed and planning \\
11 & Verbal and working memory \\
12 & Contextual memory and application of techniques to \\
& activities of daily living \\
\hline
\end{tabular}

done at home during the week. Table 2 lists the distribution of cognitive functions trained in each session. Figure 1 shows two examples of attention and memory tasks.

After each session, patients were handed a booklet with tasks to perform at home during the week. These booklets were composed of a minimum of 10 and a maximum of 30 exercises designed to reinforce the material covered in the previous session and prevent cognitive inactivity until the next session. These booklets included cancellation tasks to work attentional functions, memorization of stimuli tasks (words, numbers and images), task planning and organizing and other tasks. Figure 2 shows examples of the tasks.

The review on the degree of compliance with home training and patient feedback on their performance was one of the most important points in these booklets (only patients with a degree of compliance $\geq 80 \%$ were included in the analyses).

The last booklet contained a set of guidelines and general advice on the influence of habits and lifestyles on cognitive functions, practical exercises for working memory and the

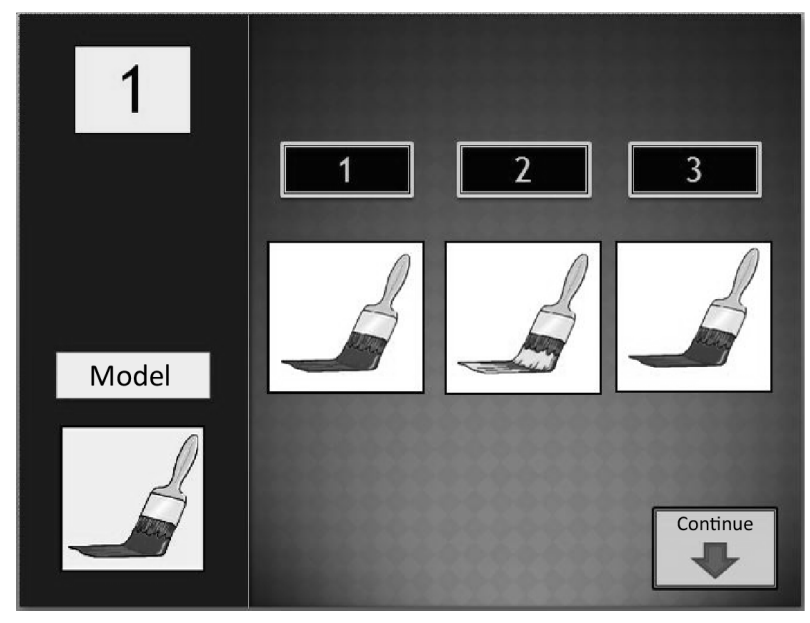

Figure I Examples of computerized tasks. ability to concentrate as well as suggestions on planning and physical activity.

\section{Statistical analysis}

Categorical variables were expressed as frequencies and percentages. Continuous variables were expressed as mean, standard deviation, median and range (min-max). Normality was tested with the Kolmogorov-Smirnov test.

The comparison between groups for continuous variables was performed using the Student's $t$-test, and the MannWhitney $U$ test was used for the comparison of categorical variables.

A repeated measures analysis of covariance (ANCOVA) with baseline and 3 months scores as dependent measures, time as a fixed factor, TG as an independent variable and age and schooling as covariates was used to test the effect of the intervention on cognitive performance.

A repeated measures analysis of variance was used to test for changes in secondary variables (subjective perception of cognitive disability, level of fatigue, anxiety and depression and quality of life).

The Pearson coefficient was used to calculate the correlation between effect sizes of change in cognitive measures and anxiety and depressive symptoms.

Statistical analysis was performed with SPSS v. 17.0 (SPSS Inc., Chicago, IL, USA). The $P$-values $<0.05$ were considered statistically significant.

\section{Results}

A total of 62 patients were included in the statistical analysis. Table 3 lists their clinical and demographic characteristics. No differences were found between groups in terms of sex,

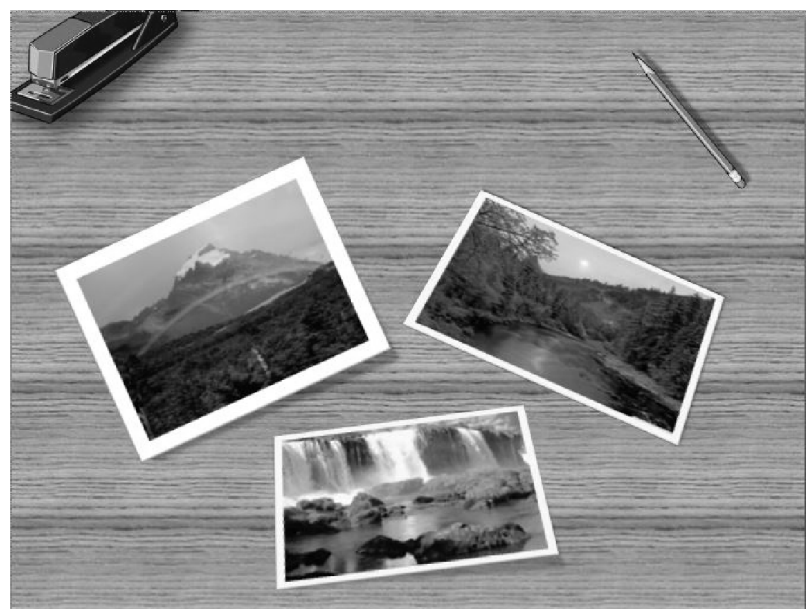




\section{Exercise 12:}

Below is a series of symbols. Some of them are repeated and others are not. Find and circle the 13 symbols that have no partner.

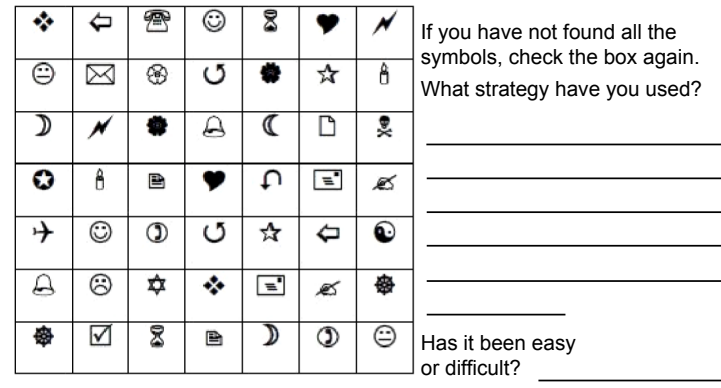

Figure 2 Examples of paper and pencil tasks.

age, level of schooling, MS course, disease duration or EDSS scores.

Both the TG and the CG were cognitively equivalent before intervention (there were no significant differences in any cognitive variable; Table 4).

ANCOVA showed the intervention effect on cognitive performance in all verbal memory measures (LTS $[P<0.05]$, CLTR $[P<0.001]$, SRT-DR $[P \leq 0.001])$, visuospatial delayed recall (SPART $[P<0.05]$ ), working memory (PASAT $[P<0.001])$, processing speed (SDMT $[P<0.05]$ ) and phonetic fluency (COWAT $[P \leq 0.05]$ ).

The CG showed no differences in cognitive performance between baseline condition and condition after 3 months, but the TG showed improvements in verbal memory, working memory and phonetic fluency.

Regarding secondary variables (Table 5), both the TG and the CG were equivalent in subjective perception of cognitive performance (MSNQ), level of fatigue (FSS) and anxiety (HADS); however, the TG showed higher scores in

Table 3 Clinical and demographic characteristics of patients

\begin{tabular}{llll}
\hline Characteristics & TG $(\mathbf{n}=\mathbf{3 0})$ & CG $(\mathbf{n}=\mathbf{3 2})$ & P-value \\
\hline Sex (female), n (\%) & $18(56.3)$ & $14(76.7)$ & 0.09 \\
Age (years) & $44.93 \pm 9.89$ & $40.88 \pm 8.50$ & 0.08 \\
Schooling (years) & $10.21 \pm 2.64$ & $11.59 \pm 3.03$ & 0.06 \\
MS course, n (\%) & & & \\
$\quad$ RR & $27(90.0)$ & $30(93.7)$ & \\
SP & $2(6.7)$ & $0(0)$ & 0.63 \\
PP & $1(3.3)$ & $2(6.3)$ & \\
Disease duration (years) & $11.50 \pm 8.05$ & $9.59 \pm 7.40$ & 0.34 \\
EDSS & $2.78 \pm 1.98$ & $2.11 \pm 1.36$ & 0.12 \\
\hline
\end{tabular}

Abbreviations: CG, control group; EDSS, Expanded Disability Status Scale; MS, multiple sclerosis; PP, primary progressive; RR, relapsing remitting; SP, secondary progressive; TG, treatment group.
Exercise 3:

Try to memorize the items below. Try to use a strategy. Take all the time you need.

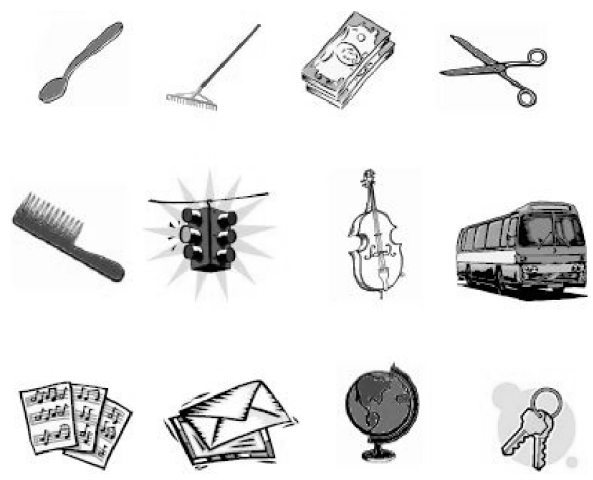

Table 4 Results of cognitive assessment

\begin{tabular}{|c|c|c|c|c|c|}
\hline Measures & TG $(n=30)$ & CG $(n=32)$ & $t / F$ & $d f$ & $P$-value \\
\hline \multicolumn{6}{|l|}{ SRT } \\
\hline \multicolumn{6}{|l|}{ LTS } \\
\hline Baseline & $26.37 \pm 15.56$ & $28.91 \pm 13.27$ & 1.93 & 1.60 & 0.49 \\
\hline 3 months & $4|.40 \pm| 4.9 \mid *$ & $34.00 \pm 16.26$ & 8.52 & 1.57 & $<0.05$ \\
\hline \multicolumn{6}{|l|}{ CLTR } \\
\hline Baseline & $17.57 \pm \mid 3.94$ & $22.03 \pm 13.89$ & 0.00 & 1.60 & 0.21 \\
\hline 3 months & $32.03 \pm 18.26^{\#}$ & $24.53 \pm 16.28$ & 14.8 & 1.57 & $<0.001$ \\
\hline \multicolumn{6}{|l|}{ SRT-DR } \\
\hline Baseline & $5.87 \pm 2.56$ & $6.03 \pm 2.87$ & 0.76 & 1.60 & 0.81 \\
\hline 3 months & $8.03 \pm 2.79 \ddagger$ & $6.22 \pm 2.86$ & 20.48 & 1.57 & $<0.001$ \\
\hline \multicolumn{6}{|c|}{ I 0/36 SPART } \\
\hline \multicolumn{6}{|c|}{ SPART - total } \\
\hline Baseline & $20.70 \pm 4.81$ & $20.47 \pm 4.50$ & 0.19 & 1.60 & 0.85 \\
\hline 3 months & $22.77 \pm 5.56$ & $21.38 \pm 4.14$ & 1.34 & 1.57 & 0.25 \\
\hline \multicolumn{6}{|l|}{ SPART-DR } \\
\hline Baseline & $6.50 \pm 2.11$ & $7.59 \pm 1.76$ & -1.82 & 1.60 & 0.06 \\
\hline 3 months & $7.87 \pm 2.21$ & $7.63 \pm I .8 I$ & 5.24 & 1.57 & $<0.05$ \\
\hline \multicolumn{6}{|l|}{ SDMT } \\
\hline Baseline & $42.00 \pm 12.72$ & $47.53 \pm 11.09$ & -1.76 & 1.60 & 0.07 \\
\hline 3 months & $46.47 \pm 13.30$ & $47.93 \pm 10.34$ & 8.13 & 1.57 & $<0.05$ \\
\hline \multicolumn{6}{|l|}{ PASAT } \\
\hline \multicolumn{6}{|c|}{ PASAT-3" correct } \\
\hline Baseline & $24.50 \pm 14.56$ & $31.18 \pm|4.4|$ & -1.77 & 1.60 & 0.07 \\
\hline 3 months & $29.70 \pm 15.48 \pi$ & $30.44 \pm 16.08$ & 22.02 & 1.57 & $<0.001$ \\
\hline \multicolumn{6}{|l|}{ COWAT } \\
\hline \multicolumn{6}{|l|}{ FAS } \\
\hline Baseline & $28.37 \pm 10.13$ & $31.88 \pm 9.69$ & -1.07 & 1.60 & 0.29 \\
\hline 3 months & $32.23 \pm 9.67 *$ & $33.13 \pm 11.21$ & 4.55 & 1.57 & $<0.05$ \\
\hline \multicolumn{6}{|l|}{ Animals } \\
\hline Baseline & $17.70 \pm 5.05$ & $19.00 \pm 4.48$ & -1.39 & 1.60 & 0.17 \\
\hline 3 months & $19.23 \pm 4.45$ & $|9.63 \pm 5.5|$ & 1.02 & 1.57 & 0.32 \\
\hline
\end{tabular}

Notes: All values are raw scores. Comparing baseline with 3 months: $* P<0.05$, ${ }^{\# P}<0.001,{ }^{\ddagger} P<0.001$, and ${ }^{\top} P \leq 0.05$.

Abbreviations: CG, control group; CLTR, consistent long-term retrieval; COWAT, Controlled Oral Word Association Test; $d f$, degree of freedom; DR, delayed recall; FAS, Phonetic fluency; LTS, long-term storage; PASAT, Paced Auditory Serial Addition Test; SDMT, Symbol Digit Modalities Test; SPART, Spatial Recall Test; SRT, Selective Reminding Test; TG, treatment group. 
Table 5 Questionnaire results at baseline and at 3 months

\begin{tabular}{|c|c|c|c|c|c|}
\hline Measures & TG $(n=30)$ & CG $(n=32)$ & $t / F$ & $d f$ & $P$-value \\
\hline \multicolumn{6}{|l|}{ MSNQ } \\
\hline Baseline & $29.83 \pm 11.99$ & $24.28 \pm 11.57$ & 2.41 & 1.60 & 0.07 \\
\hline 3 months & $23.87 \pm 11.83^{*}$ & $25.63 \pm 11.83$ & 16.55 & 1.60 & $<0.001$ \\
\hline \multicolumn{6}{|l|}{ FSS } \\
\hline Baseline & $34.73 \pm 21.97$ & $28.89 \pm 21.79$ & 1.05 & 1.60 & 0.29 \\
\hline 3 months & $30.5 \mathrm{I} \pm 20.22$ & $29.21 \pm 21.94$ & 1.44 & 1.60 & 0.24 \\
\hline \multicolumn{6}{|l|}{ HADS } \\
\hline \multicolumn{6}{|l|}{ Anxiety } \\
\hline Baseline & $8.10 \pm 4.18$ & $6.50 \pm 3.39$ & 1.66 & 1.60 & 0.10 \\
\hline 3 months & $5.97 \pm 3.15^{\#}$ & $7.4 I \pm 3.44^{\#}$ & 17.52 & 1.60 & $<0.001$ \\
\hline \multicolumn{6}{|l|}{ Depression } \\
\hline Baseline & $7.47 \pm 3.29$ & $5.75 \pm 3.63$ & 2.11 & 1.60 & 0.05 \\
\hline 3 months & $5.57 \pm 3.93$ & $6.13 \pm 3.49$ & $|2.3|$ & 1.60 & $<0.001$ \\
\hline \multicolumn{6}{|l|}{ MSQoL-54 } \\
\hline \multicolumn{6}{|l|}{ Physical } \\
\hline Baseline & $46.43 \pm 17.83$ & $63.75 \pm 17.27$ & -3.88 & 1.60 & $<0.001$ \\
\hline 3 months & $52.99 \pm 19.20 \pi$ & $63.24 \pm 16.98$ & 4.57 & 1.60 & $<0.05$ \\
\hline \multicolumn{6}{|l|}{ Mental } \\
\hline Baseline & $47.88 \pm 20.19$ & $62.16 \pm 16.27$ & -3.07 & 1.60 & 0.03 \\
\hline 3 months & $56.39 \pm 18.70^{\ddagger}$ & $67.32 \pm 17.06$ & 1.18 & 1.60 & 0.28 \\
\hline
\end{tabular}

Notes: All values are raw scores. Comparing baseline with 3 months: $* P<0.00$ I, ${ }^{\#} P<0.05,{ }^{\ddagger} P<0.05$ and $\pi P<0.05$.

Abbreviations: CG, control group; $d f$, degree of freedom; FSS, Fatigue Severity Scale; HADS, Hospital Anxiety and Depression Scale; MSNQ, Multiple Sclerosis Neuropsychological Questionnaire; MSQoL-54, Multiple Sclerosis Quality of Life-54; TG, treatment group.

depression (HADS) at the beginning of the treatment. The CG had higher quality of life (physical and mental).

After intervention, the TG had a significant decrease in anxiety symptoms, a significantly lower score in MSNQ and higher quality of life, both physical and mental. ANCOVA showed a positive effect of the treatment on MSNQ $(P<0.001)$, anxiety $(P<0.001)$, depression $(P<0.001)$ and physical quality of life $(P<0.001)$.

Regarding effect size in cognitive measures, anxiety showed a negative correlation with CLTR $(F=-0.436$, $P=0.26$ ) and the same trend in the remaining variables but without statistical significance.

\section{Discussion}

Neurodegenerative conditions such as dementia, Parkinson's disease and MS are often characterized by a significant neuropsychological deficit worsening the quality of life of patients and reducing their occupational profile and social participation. ${ }^{41-43}$ Cognitive rehabilitation could be a useful tool in reducing the impairment and/or maintaining the cognitive status, although the results of research conducted on this are inconclusive.

We have developed a multi-domain computer-assisted cognitive program supported by home-based work for 3 months to train cognitive functions in patients with MS.
The main result of the present study is that this type of intervention can be effective to improve some of major cognitive functions, which are affected in patients with MS: verbal memory, working memory, processing speed and phonetic fluency. The exercises induced significantly better results on both the objective and subjective perception of cognitive impairment compared with a non-cognitive-specific intervention receiving information about cognitive functions and status and some advice about them.

The benefits of rehabilitation in cognition have been documented in several studies, and our data are consistent with the literature. The results obtained in the present study are similar to those found by Brissart et al, ${ }^{21}$ who used a nonspecific training in which multiple cognitive domains are worked. In this case, the TG showed an increase in several cognitive measures. For their part, Shatil et al ${ }^{20}$ obtained similar results with a more intensive computer-aided intervention program with three training sessions per week. Other studies have also shown the positive effects of computerized training of different cognitive domains, even in the perception of improvement in cognitive deficits. ${ }^{22}$

Unlike most of the abovementioned studies, the present study applies a combination of computer-assisted work (weekly training has been focused on teaching of memorization techniques, organization of information or planning and direct training on attention functions, working memory and processing speed) and self-training at home to reinforce the cognitive strategies, putting these strategies into practice and avoiding inactivity between sessions. The training program had positive results, both in cognitive variables and in the subjective perception of cognitive status. Finally, the program was less intensive and shorter in time. The authors believe that the combination of the two types of training allows the same positive results to be obtained as longer workouts that only include one treatment modality.

As regards working memory, this impairment is well known in patients with MS, but not many studies have demonstrated improvement resulting from intervention. ${ }^{21,44}$

These results suggest that our intervention protocol is at least partially effective in improving cognitive functions, although other possible explanations should be considered.

First, the results may be related to the effect of practice, although the CG did not show better performance in any of the variables analyzed and this effect was controlled by using alternative versions of the same battery. However, with the aim of avoiding the regression to the mean, both the experimental group and the $\mathrm{CG}$ were equivalent on all clinical (EDSS score, MS course, disease duration), demographic (sex, age, schooling) and neuropsychological variables. 
In addition, the possible effect of baseline performance on the 3-month performance was controlled by including a repeated measures model in the analyses.

Second, patients were not blinded to the intervention group, and it is also possible that the results were influenced by this, which could contribute to and increase the placebo effect of the patients included in the TG and a tendency to not perceive cognitive changes in patients of the waiting group.

It is noteworthy that, in the present study, the patients who received cognitive training also showed a significant decrease in the anxiety score but not in the depression score. The high prevalence of psychiatric concerns, such as depression and anxiety, has been well documented in patients with MS. ${ }^{45}$ It seems that depression symptoms and anxiety symptoms may involve different processes within $\mathrm{MS} .{ }^{46} \mathrm{We}$ believe that anxiety could be related to the feeling of lack of control over various aspects of the disease and with the anticipation of negative consequences. Both the CG and TG were informed about the implications of cognitive deterioration and received advice about them. The TG showed a significant lower score on anxiety measures. As regards depression, the pattern of change is equivalent but the scores are not significantly lower. It is possible, with a slightly larger sample, that the decline in depression would be significant as well. The improvement in emotional symptoms after periods of cognitive treatment has already been described by other authors. ${ }^{47,48}$

Since there were already differences in quality of life between the two groups before the intervention (the CG had a higher baseline MSQoL in both physical and mental domains and lower depressive scores, this might reflect a better neuropsychiatric/quality of life status in this group). Thus, the more likely explanation for these differences is an effect of regression to the mean, and therefore, improving this could not be associated with the treatment carried out.

This study indicates the usefulness of combining computer-aided training and self-training at home for treating memory deficits present in patients with MS, and the improvement found has encouraged us to continue studying strategies to counteract cognitive damage arising from MS and to develop studies with a longer follow-up period to verify the persistence of the positive effect.

The main limitation of this study is the absence of a placebo group. The CG did not have any comparable interaction with the caregiver; they were contacted once a week, but did not have the 12 sessions of physician contact compared to the real-TG. The "medical care itself" (seeing the physician, filling in the questionnaires, hospital setting, follow-ups) can contribute to the patients' well-being and might have contributed to the positive results seen in the real TG.

\section{Conclusion}

Cognitive intervention with a computer-assisted training supported by home training between face sessions is a useful tool to treat patients with MS and improve functions such as verbal memory, working memory and phonetic fluency through learning and subsequent consolidation of strategies and techniques of organization of the information.

\section{Acknowledgments}

We would like to thank Patrick Dennis for his help in revising the English in this manuscript. This study has been carried out without funding sources.

\section{Disclosure}

The authors report no conflicts of interest in this work.

\section{References}

1. Pflugshaupt T, Geisseler O, Nyffeler T, Linnebank M. Cognitive impairment in multiple sclerosis: clinical manifestation, neuroimaging correlates, and treatment. Semin Neurol. 2016;36(2):203-211.

2. Jonkman LE, Rosenthal DM, Sormani MP, et al. Gray matter correlates of cognitive performance differ between relapsing-remitting and primaryprogressive multiple sclerosis. PLoS One. 2015;10(10):e0129380.

3. Tur C, Penny S, Khaleeli Z, et al. Grey matter damage and overall cognitive impairment in primary progressive multiple sclerosis. Mult Scler. 2011;17(11):1324-1332.

4. Amato MP, Zipoli V, Portaccio E. Multiple sclerosis-related cognitive changes: a review of cross-sectional and longitudinal studies. J Neurol Sci. 2006;245(1-2):41-46.

5. Piras MR, Magnano I, Canu ED, et al. Longitudinal study of cognitive dysfunction in multiple sclerosis: neuropsychological, neuroradiological, and neurophysiological findings. J Neurol Neurosurg Psychiatry. 2003; 74(7):878-885.

6. Reuter F, Zaaraoui W, Crespy L, et al. Frequency of cognitive impairment dramatically increases during the first 5 years of multiple sclerosis. J Neurol Neurosurg Psychiatry. 2011;82(10):1157-1159.

7. Beatty WW, Monson N. Problem solving by patients with multiple sclerosis: comparison of performance on the Wisconsin and California Card Sorting Tests. J Int Neuropsychol Soc. 1996;2(2):134-140.

8. Calabrese P. Neuropsychology of multiple sclerosis - an overview. J Neurol. 2006;253(suppl 1):I10-I15.

9. Bobholz JA, Rao SM. Cognitive dysfunction in multiple sclerosis: a review of recent developments. Curr Opin Neurol. 2003;16(3): 283-288.

10. Pompeii LA, Moon SD, McCrory DC. Measures of physical and cognitive function and work status among individuals with multiple sclerosis: a review of the literature. J Occup Rehabil. 2005;15(1):69-84.

11. Putzki N, Fischer J, Gottwald K, et al; "Mensch im Mittelpunkt” Study Group. Quality of life in 1000 patients with early relapsing-remitting multiple sclerosis. Eur J Neurol. 2009;16(6):713-720.

12. Schiavolin S, Leonardi M, Giovannetti AM, et al. Factors related to difficulties with employment in patients with multiple sclerosis: a review of 2002-2011 literature. Int J Rehabil Res. 2013;36(2):105-111.

13. Engel C, Greim B, Zettl UK. Diagnostics of cognitive dysfunctions in multiple sclerosis. J Neurol. 2007;254(suppl 2):II30-II34.

14. Rao SM, Leo GJ, Ellington L, Nauertz T, Bernardin L, Unverzagt F. Cognitive dysfunction in multiple sclerosis. II. Impact on employment and social functioning. Neurology. 1991;41(5):692-696.

15. Plohmann AM, Kappos L, Ammann W, et al. Computer assisted retraining of attentional impairments in patients with multiple sclerosis. J Neurol Neurosurg Psychiatry. 1998;64(4):455-462. 
16. Amato MP, Goretti B, Viterbo RG, et al. Computer-assisted rehabilitation of attention in patients with multiple sclerosis: results of a randomized, double-blind trial. Mult Scler. 2014;20(1):91-98.

17. Cerasa A, Gioia MC, Valentino P, et al. Computer-assisted cognitive rehabilitation of attention deficits for multiple sclerosis: a randomized trial with fMRI correlates. Neurorehabil Neural Repair. 2013;27(4): 284-295.

18. Chiaravalloti ND, DeLuca J, Moore NB, Ricker JH. Treating learning impairments improves memory performance in multiple sclerosis: a randomized clinical trial. Mult Scler. 2005;11(1):58-68.

19. Stuifbergen AK, Becker H, Perez F, Morison J, Kullberg V, Todd A. A randomized controlled trial of a cognitive rehabilitation intervention for persons with multiple sclerosis. Clin Rehabil. 2012;26(10): 882-893.

20. Shatil E, Metzer A, Horvitz O, Miller A. Home-based personalized cognitive training in MS patients: a study of adherence and cognitive performance. NeuroRehabilitation. 2010;26(2):143-153.

21. Brissart H, Leroy M, Morele E, Baumann C, Spitz E, Debouverie M. Cognitive rehabilitation in multiple sclerosis. Neurocase. 2013;19(6): 553-565.

22. Rosti-Otajärvi E, Mäntynen A, Koivisto K, Huhtala H, Hämäläinen P. Neuropsychological rehabilitation has beneficial effects on perceived cognitive deficits in multiple sclerosis during nine-month follow-up. J Neurol Sci. 2013;334(1-2):154-160.

23. De Giglio L, De Luca F, Prosperini L, et al. A low-cost cognitive rehabilitation with a commercial video game improves sustained attention and executive functions in multiple sclerosis: a pilot study. $J$ Neurol Rehabil. 2015;29(5):453-461.

24. Mäntynen A, Rosti-Otajärvi E, Koivisto K, Lilja A, Huhtala H, Hämäläinen P. Neuropsychological rehabilitation does not improve cognitive performance but reduces perceived cognitive deficits in patients with multiple sclerosis: a randomised, controlled, multi-centre trial. Mult Scler. 2014;20(1):99-107.

25. WMA [webpage on the Internet]. Declaration of Helsinki-Ethical Principles for Medical Research Involving Human Subjects. 2013. Available from: http:/www.wma.net/es/30publications/10policies/b3/. Accessed January 9, 2016.

26. Polman CH, Reingold SC, Edan G, et al. Diagnostic criteria for multiple sclerosis: 2005 revisions to the 'McDonald Criteria'. Ann Neurol. 2005;58(6):840-846.

27. Kurtzke JF. Rating neurologic impairment in multiple sclerosis: an expanded disability status scale (EDSS). Neurology. 1983;33(11): 1444-1452.

28. American Psychiatric Association. Diagnostic and Statistical Manual of Mental Disorders: DSM-IV-TR. Washington DC: American Psychiatric Association; 2000

29. Rao SM. A Manual for the Brief Repeatable Battery of Neuropsychological Tests in Multiple Sclerosis. Milwaukee, WI: Medical College of Wisconsin; 1990.

30. Buschke H. Selective reminding for analysis of memory and learning. J Verbal Learn Verbal Behav. 1973;12:543-550.

31. Barbizet J, Cany E. Clinical and psychometrical study of a patient with memory disturbances. Int J Neurol. 1968;7(1):44-54.
32. Smith A. Symbol Digit Modalities Test: Manual. LA: Western Psychological Services; 1991.

33. Gronwall DM. Paced auditory serial-addition task: a measure of recovery from concussion. Percept Mot Skills. 1977;44(2):367-373.

34. Spreen O, Benton AL. Neurosensory Center Comprehensive Examination for Aphasia: Manual of Directions. Victoria, BC: Neuropsychology Laboratory; 1969.

35. Sepulcre J, Vanotti S, Hernández R, et al. Cognitive impairment in patients with multiple sclerosis using the brief repeatable batteryneuropsychology test. Mult Scler. 2006;12(2):187-195.

36. Troyer AK. Normative data for clustering and switching on verbal fluency tasks. J Clin Exp Neuropsychol. 2000;22(3):370-378.

37. Benedict RH, Munschauer F, Linn R, et al. Screening for multiple sclerosis cognitive impairment using a self-administered 15-item questionnaire. Mult Scler. 2003;9(1):95-101.

38. Krupp LB, LaRocca NG, Muir-Nash J, Steinberg AD. The fatigue severity scale. Application to patients with multiple sclerosis and systemic lupus erythematosus. Arch Neurol. 1989;46(10):1121-1123.

39. Zigmond AS, Snaith RP. The hospital anxiety and depression scale. Acta Psychiatr Scand. 1983;67:361-370.

40. Vickrey BG, Hays RD, Harooni R, Myers LW, Ellison GW. A healthrelated quality of life measure for multiple sclerosis. Qual Life Res. 1995; 4(3):187-206.

41. Borghi M, Cavallo M, Carletto S, et al. Presence and significant determinants of cognitive impairment in a large sample of patients with multiple sclerosis. PLoS One. 2013;8(7):e69820.

42. Cavallo M, Cavanna AE, Harciarek M, Johnston H, Ostacoli L, Angilletta C. 'Keep up the good work'! A case study of the effects of a specific cognitive training in Alzheimer's disease. Neurocase. 2013;19(6): $542-552$.

43. Ding W, Ding L-J, Li F-F, Han Y, Mu L. Neurodegeneration and cognition in Parkinson's disease: a review. Eur Rev Med Pharmacol Sci. 2015;19(12):2275-2281.

44. Vogt A, Kappos L, Calabrese P, et al. Working memory training in patients with multiple sclerosis - comparison of two different training schedules. Restor Neurol Neurosci. 2009;27(3):225-235.

45. Marrie RA, Hanwell H. General health issues in multiple sclerosis: comorbidities, secondary conditions, and health behaviors. Continuum (Minneap Minn). 2013;19(4 Multiple Sclerosis):1046-1057.

46. Lester K, Stepleman L, Hughes M. The association of illness severity, self-reported cognitive impairment, and perceived illness management with depression and anxiety in a multiple sclerosis clinic population. J Behav Med. 2007;30(2):177-186.

47. Brenk A, Laun K, Haase CG. Short-term cognitive training improves mental efficiency and mood in patients with multiple sclerosis. Eur Neurol. 2008;60(6):304-309.

48. Mendoza RJ, Pittenger DJ, Weinstein CS. Unit management of depression of patients with multiple sclerosis using cognitive remediation strategies: a preliminary study. J Neurol Rehabil. 2001;15(1):9-14.

49. Mattioli F, Stampatori C, Zanotti D, Parrinello G, Capra R. Efficacy and specificity of intensive cognitive rehabilitation of attention and executive functions in multiple sclerosis. J Neurol Sci. 2010;288(1-2): 101-105.
Neuropsychiatric Disease and Treatment

\section{Publish your work in this journal}

Neuropsychiatric Disease and Treatment is an international, peerreviewed journal of clinical therapeutics and pharmacology focusing on concise rapid reporting of clinical or pre-clinical studies on a range of neuropsychiatric and neurological disorders. This journal is indexed on PubMed Central, the 'PsycINFO' database and CAS,

\section{Dovepress}

and is the official journal of The International Neuropsychiatric Association (INA). The manuscript management system is completely online and includes a very quick and fair peer-review system, which is all easy to use. Visit http://www.dovepress.com/testimonials.php to read real quotes from published authors. 